\title{
Mechanism and Durability of Repair Systems in Polymer-Modified Cement Mortars
}

\author{
Ru Wang and Liang Zhang \\ Key Laboratory of Advanced Civil Engineering Materials of Ministry of Education, School of Materials Science and Engineering, \\ Tongji University, 4800 Cao'an Road, Shanghai 201804, China
}

Correspondence should be addressed to Ru Wang; ruwang@tongji.edu.cn

Received 24 October 2014; Accepted 8 June 2015

Academic Editor: Dachamir Hotza

Copyright (c) 2015 R. Wang and L. Zhang. This is an open access article distributed under the Creative Commons Attribution License, which permits unrestricted use, distribution, and reproduction in any medium, provided the original work is properly cited.

\begin{abstract}
This paper investigated the mechanism and durability of repair systems made of ordinary cement-based repair mortar and three kinds of polymer-modified repair mortars with old concrete, SBR dispersion, SAE dispersion, and SAE powder. By comparing the bonding properties of mortars before and after erosion, it was found that polymers could effectively improve the durability of the repair system and SAE powder had the best improvement. Micromorphology study of the repair mortar and the interface of repair mortar with old concrete through SEM showed that the polymer film formed from SAE powder whatever in the mortar or at the interface was dense and tough, the film formed from SAE dispersion was loose and weak, while the film formed from SBR dispersion was in between them, which explained the difference in the tensile bond strength and the durability of the repair systems.
\end{abstract}

\section{Introduction}

Concrete is the most common and versatile building material in the world. With the growth of operational life, the construction damage caused by improper design, management and poor durability of material, and so forth, often occurs. It not only affected the normal usage of construction but also caused huge economic losses. Therefore, the repair and reinforcement of the damaged structures are the important issues for the construction industry today.

Polymer-modified cement mortar has been widely used as repair mortar due to its high strength, good durability, and good bonding properties to old concrete constructions. Researchers had studied the mechanical properties of polymer-modified mortar used for repairing and the results showed that polymer could greatly improve the mortar repair performance [1-3]. Additionally, the polymer was reported to be able to improve the durability of repair mortar which was an important aspect to be considered in construction [4-6].

For the construction repair, only improvement of the repair material properties is not enough; we need to consider the whole system consisting of repair materials and the old concrete. Morgan [7] believed that the performance of system determined the quality of repair in which the interface between repair mortar and old concrete exerted the most important impact. Many bonding mechanisms of the system interface were reported by now. Morgan thought the interface of repair mortar and old concrete could be seen as cementaggregate interface, in which the old concrete was like a big aggregate. Bijen and Salet [8] made a point that mortar and old concrete were bonded though Van der Waals force, mechanical bite force, and surface tension. While Emmons and Vaysburd [9] adopted three-zone bonding model that included new material zone, interface zone, and old material zone to study the interface, there were some other studies about the interface mechanisms [10,11], but little study was based on the modification mechanism of polymer on the interface.

In this paper, three kinds of polymer-modified cementbased mortars were used as repair mortars. By placing the bonded repair mortar and old concrete into erosion environment the effect of polymer on the durability of the repair system was studied. The morphology of the repair mortar and the interface between repair mortar and old concrete 
TABLE 1: Chemical composition of P.II 52.5R Portland cement (\% by weight).

\begin{tabular}{lcccccccccc}
\hline $\mathrm{CaO}$ & $\mathrm{SiO}_{2}$ & $\mathrm{Al}_{2} \mathrm{O}_{3}$ & $\mathrm{Fe}_{2} \mathrm{O}_{3}$ & $\mathrm{SO}_{3}$ & $\mathrm{MgO}$ & $\mathrm{K}_{2} \mathrm{O}$ & $\mathrm{Na}_{2} \mathrm{O}$ & $\mathrm{f}-\mathrm{CaO}$ & Loss on ignition & Insoluble residue \\
\hline 62.72 & 20.24 & 5.29 & 3.4 & 1.97 & 1.18 & 0.57 & 0.11 & 0.23 & 2.47 & 0.94 \\
\hline
\end{tabular}

TABLE 2: The parameters of polymers.

\begin{tabular}{lccccccc}
\hline & $\begin{array}{c}\text { Solid content } \\
(\%)\end{array}$ & $\begin{array}{c}\text { Viscosity } \\
(\mathrm{mPa} \cdot \mathrm{s})\end{array}$ & $\begin{array}{c}\text { Bulk density } \\
\left(\mathrm{g} \cdot \mathrm{cm}^{-3}\right)\end{array}$ & $\mathrm{pH}$ value & $\begin{array}{c}\text { Min film formation } \\
\text { temp. }\left({ }^{\circ} \mathrm{C}\right)\end{array}$ & $\begin{array}{c}\text { Glass transition } \\
\text { temp. }\left({ }^{\circ} \mathrm{C}\right)\end{array}$ & $\begin{array}{c}\text { Ash content } \\
(\% \text { by weight })\end{array}$ \\
\hline SBR dispersion & 51 & $35-100$ & - & $7.8 \sim 10$ & $15 \sim 21$ & -3 & - \\
SAE dispersion & 57 & $50-150$ & - & $7.0 \sim 8.5$ & 1 & -6 & - \\
SAE powder & - & - & 0.5 & 8.0 & 0 & 15 & 9.5 \\
\hline
\end{tabular}

TABle 3: Mix proportions of mortar in weight ratio.

\begin{tabular}{ccccccc}
\hline & Cement & SBR dispersion (solid part) & SAE dispersion (solid part) & SAE powder & Sand & $m_{w} / m_{c}$ \\
\hline $\mathrm{R}$ & 100 & 0 & 0 & 0 & 300 \\
$\mathrm{~A}$ & 100 & 10 & 0 & 0 & 0.44 \\
$\mathrm{~B}$ & 100 & 0 & 10 & 0 & 300 \\
$\mathrm{C}$ & 100 & 0 & 0 & 10 & 300 & 0.35 \\
\hline
\end{tabular}

was studied using SEM and the modification mechanism by polymer was analyzed.

\section{Experiment Program}

2.1. Raw Material. The cement used in this investigation was P.II 52.5R Portland cement and the chemical composition was shown in Table 1. Tap water and standard sand were used in this experiment. Three kinds of polymers, SBR (styrenebutadiene rubber) dispersion (SD 623), SAE (styrene acrylic ester) dispersion (S $400 \mathrm{~F}$ ), and SAE powder (FX 7000), were used to modify the ordinary repair mortar. The parameters of these three polymers were shown in Table 2.

2.2. Mix Proportion. The mix proportions of the repair mortars used in the investigation were listed in Table 3.

\subsection{Test Methods}

2.3.1. Flow. The flow table values of fresh mortars were measured according to GB/T 2419-2005. A cone-shaped metal ring was filled with fresh mortar on a shaking table, and after the ring lifted, the mortar mix was subjected to 25 table vibrations within 25 seconds. The final diameter of the mortar mix spread on the table was the so-called flow table value. The water to cement ratio $\left(m_{w} / m_{c}\right)$ of the mortar was determined by fixing the flow table value at a constant of $(170 \pm 5) \mathrm{mm}$, as listed in Table 3.

2.3.2. Tensile Bond Strength and Treating Methods for Durability Tests. The mixing of the mortar was done according to GB/T 17671-1999 (ISO679: 1989). The measurement of tensile bond strength was based on the German standard DIN 18555-5. The mixed mortar was filled into a cubic model with size of $50 \mathrm{~mm} \times 50 \mathrm{~mm} \times 5 \mathrm{~mm}$ that was placed on the old concrete. The samples were unmolded after being cured at $23^{\circ} \mathrm{C} / \mathrm{RH} 50 \%$ for 24 hours and then cured at the same environment to designed ages.

Strong bonding affinity to the old concrete is the most important property required for repair system, so the erosion resistance of repair system was measured by the reduction of the tensile bond strength after erosion. The treating methods for the durability tests were listed in the following:

(1) Acid-Base Erosion Treatment. After being cured for 14 days at $23^{\circ} \mathrm{C} / \mathrm{RH} 50 \%$, the samples were soaked in the erosion solution for 28 days. Erosion solution: $5 \% \mathrm{HCl}$ (by weight), $5 \% \mathrm{H}_{2} \mathrm{SO}_{4}$ (by weight), and saturated $\mathrm{NaOH}$ solution.

(2) Freeze-Thaw Cycle Treatment. After being cured for 28 days at $23^{\circ} \mathrm{C} / \mathrm{RH} 50 \%$, the samples were soaked in water $\left(15^{\circ} \mathrm{C} \sim 20^{\circ} \mathrm{C}\right)$ for 4 hours and then transferred into frozen environment $\left(-15^{\circ} \mathrm{C} \sim-20^{\circ} \mathrm{C}\right)$ for 6 hours. This freeze-thaw procedure was repeated for 25 cycles.

(3) Wet-Dry Cycle Treatment. After being cured for 28 days, the samples were treated for 15 cycles following the procedure of soaking in $(20 \pm 5)^{\circ} \mathrm{C}$ water for 2 hours, $(20 \pm 5)^{\circ} \mathrm{C}$ air for 0.5 hours, $(60 \pm 5)^{\circ} \mathrm{C}$ drying for 7 hours, and then $(20 \pm 5)^{\circ} \mathrm{C}$ air for 14.5 hours.

2.3.3. Microstructure Observation. The microstructure was observed by using Quanta 200 FEG SEM. In order to observe the polymer morphology clearly all samples were soaked in $5 \% \mathrm{HCl}$ solution for 5 minutes and cleaned with alcohol, and then the measurement was conducted after drying at $40^{\circ} \mathrm{C}$.

\section{Results and Discussion}

\subsection{Durability of Repair System}

3.1.1. Tensile Bond Strength. Figure 1 presents the relationship of the tensile bond strength of repair mortar with age. It 


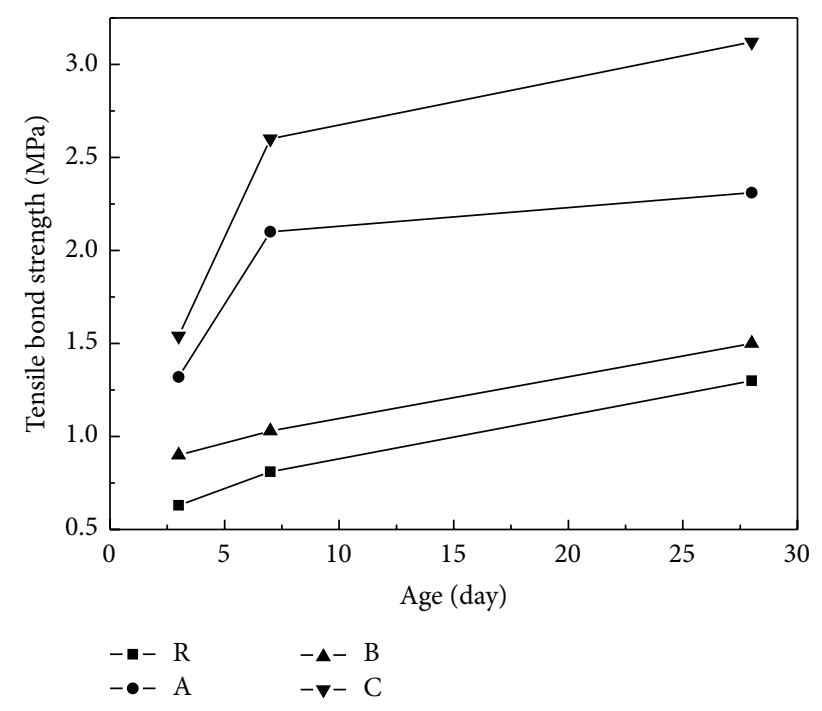

FigURE 1: Relationship of tensile bond strength of repair mortars with age.

could be seen that the polymer-modified repair mortars had better tensile bond property than ordinary cement mortar did. The SAE powder-modified repair mortar had the highest tensile bond strength that reached $1.54 \mathrm{MPa}, 2.60 \mathrm{MPa}$, and 3.12 MPa after 3-, 7-, and 28-day cure, respectively whereas the SAE dispersion-modified repair mortar had the lowest tensile bond strength among the three kinds of polymer-modified repair mortars. The tensile bond strength of SBR dispersionand SAE powder-modified mortars showed similar growth trend with age; that is, the strength grew rapidly from 3 to 7 days and then slowly between 7 and 28 days. The tensile bond strength of SAE dispersion-modified repair mortar and ordinary repair mortar had similar growth trend; that is, it increased slowly all the time.

3.1.2. Resistance to $\mathrm{HCl}$ Erosion. Figure 2 presents the tensile bond strength of repair mortars before and after erosion by $5 \% \mathrm{HCl}$ solution. It showed that the tensile bond strength of all the repair mortars decreased after erosion. The tensile bond strength decreased by $25.4 \%, 13.0 \%, 14.7 \%$, and $8.0 \%$, from 1.30 to $0.97 \mathrm{MPa}, 2.31$ to $2.01 \mathrm{MPa}, 1.50$ to $1.28 \mathrm{MPa}$, and 3.12 to $2.87 \mathrm{MPa}$, for ordinary repair mortar, SBR dispersion-, SAE dispersion-, and SAE powder-modified repair mortars, respectively. The tensile bond strength reduction of polymermodified repair mortars was much smaller than ordinary repair mortar, and thus it could be drawn that polymer could improve the $\mathrm{HCl}$ erosion resistance of the repair system. The function of SAE powder was the greatest.

3.1.3. Resistance to $\mathrm{H}_{2} \mathrm{SO}_{4}$ Erosion. Figure 3 shows the tensile bond strength of repair mortars before and after erosion by $5 \% \mathrm{H}_{2} \mathrm{SO}_{4}$ solution. After erosion, the tensile bond strength of all the repair mortars decreased but in different levels. The tensile bond strength of ordinary repair mortar decreased by $27.7 \%$. However, the reduction of the tensile bond strength of SAE powder-modified repair mortar was only $6.0 \%$. The

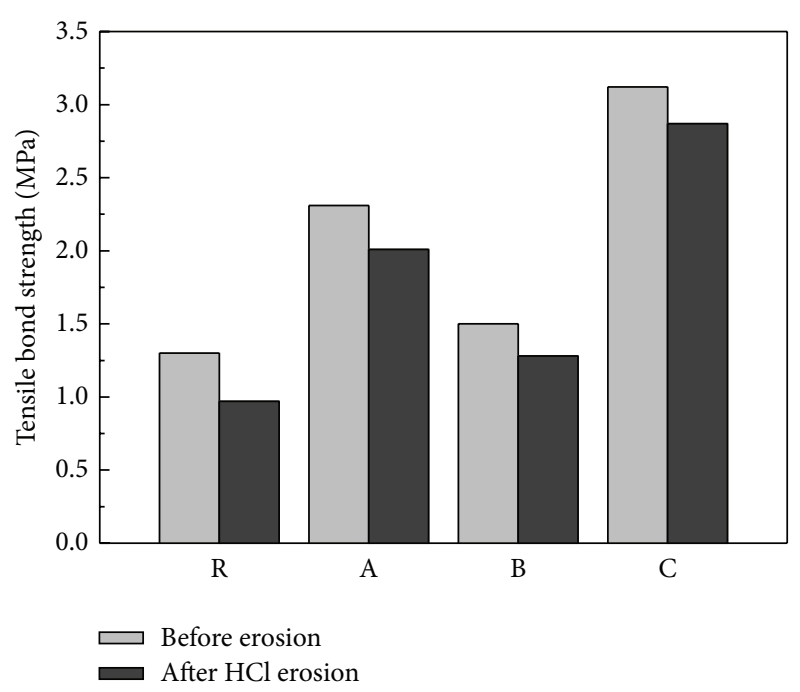

FIGURE 2: Tensile bond strength of repair mortars before and after erosion by $5 \% \mathrm{HCl}$ solution.

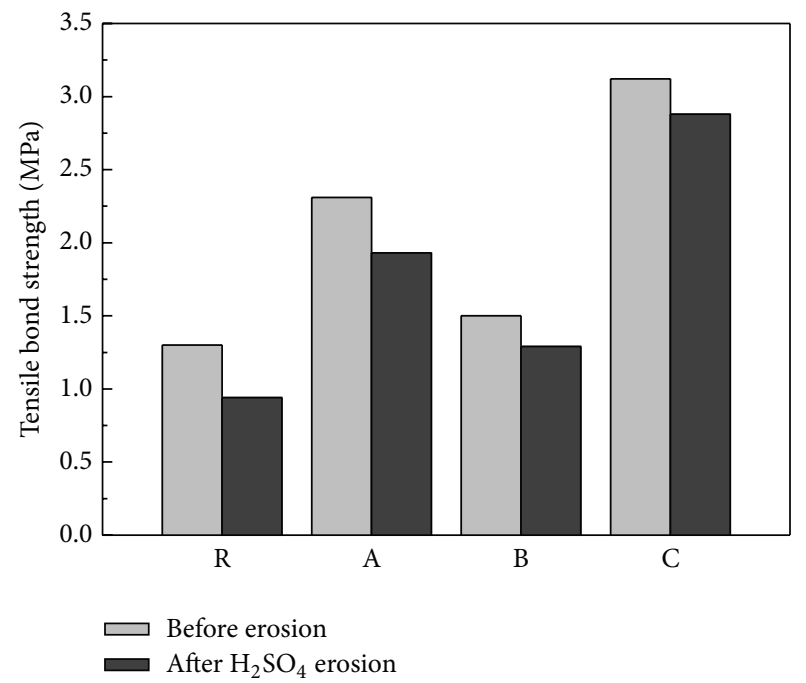

Figure 3: Tensile bond strength of repair mortars before and after erosion by $5 \% \mathrm{H}_{2} \mathrm{SO}_{4}$ solution.

reduction of the tensile bond strength of SBR dispersionand SAE dispersion-modified repair mortar was $16.4 \%$ and $14.0 \%$, respectively. It could be drawn that the polymers could improve the $\mathrm{H}_{2} \mathrm{SO}_{4}$ erosion resistance of the repair system. Among the three kinds of polymers, SAE powder had the best improvement, while the improvement by SBR dispersion was the poorest.

3.1.4. Resistance to $\mathrm{NaOH}$ Erosion. Figure 4 shows the tensile bond strength of repair mortars before and after erosion by saturated $\mathrm{NaOH}$ solution. After $\mathrm{NaOH}$ erosion, the reduction of the tensile bond strength was much smaller than that during acid erosion mentioned above. The tensile bond strength of ordinary repair mortar was decreased by $7.7 \%$. The reduction of the tensile bond strength of SBR dispersion-, 


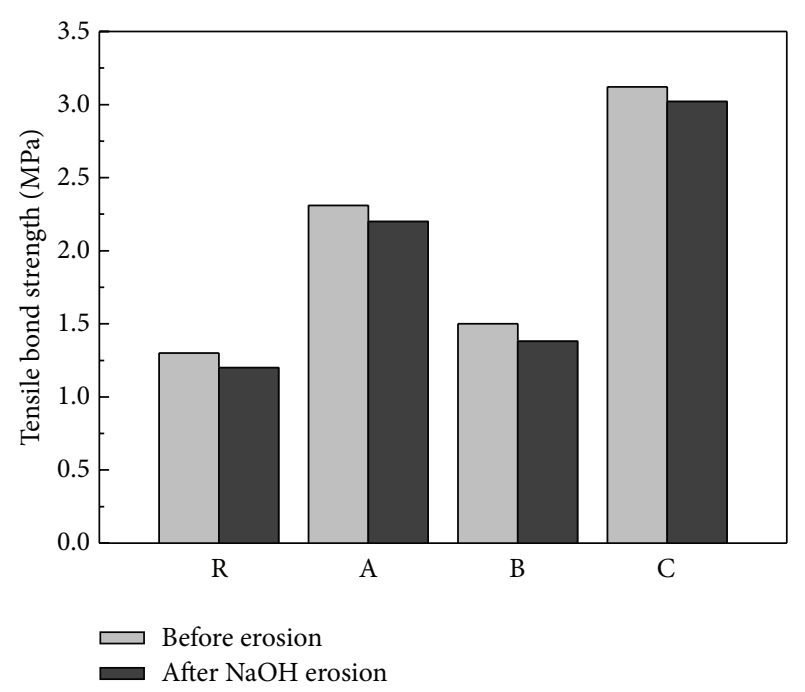

Figure 4: Tensile bond strength of repair mortars before and after erosion by saturated $\mathrm{NaOH}$ solution.

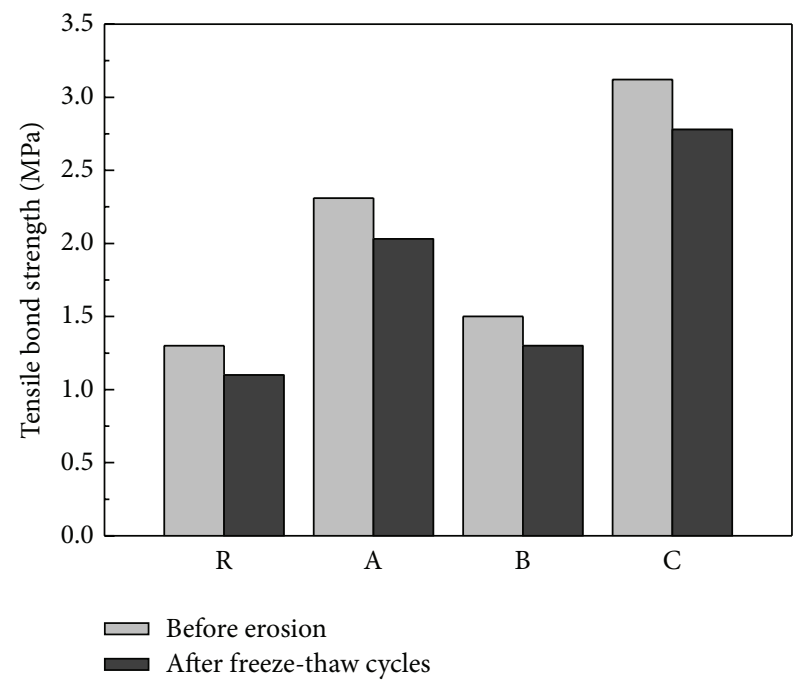

FIGURE 5: Tensile bond strength of repair mortars before and after freeze-thaw cycles.

SAE dispersion-, and SAE powder-modified repair mortar was $4.7 \%, 8.0 \%$, and $3.2 \%$, respectively. It can be found that the SAE powder and SBR dispersion had slight improvement on the $\mathrm{NaOH}$ erosion resistance of the repair system.

3.1.5. Resistance to Freeze-Thaw Cycle. Figure 5 illustrates the tensile bond strength of repair mortars before and after freethaw cycles. It revealed that after 25 freeze-thaw cycles the tensile bond strength of all the repair mortars decreased. The tensile bond strength of ordinary repair mortar was reduced by $15.4 \%$, while that of SBR dispersion-, SAE dispersion-, and SAE powder-modified repair mortars reduced by $12.1 \%$, $13.0 \%$, and $11.0 \%$, respectively. So it could be seen that the polymers could improve the resistance to freeze-thaw cycles

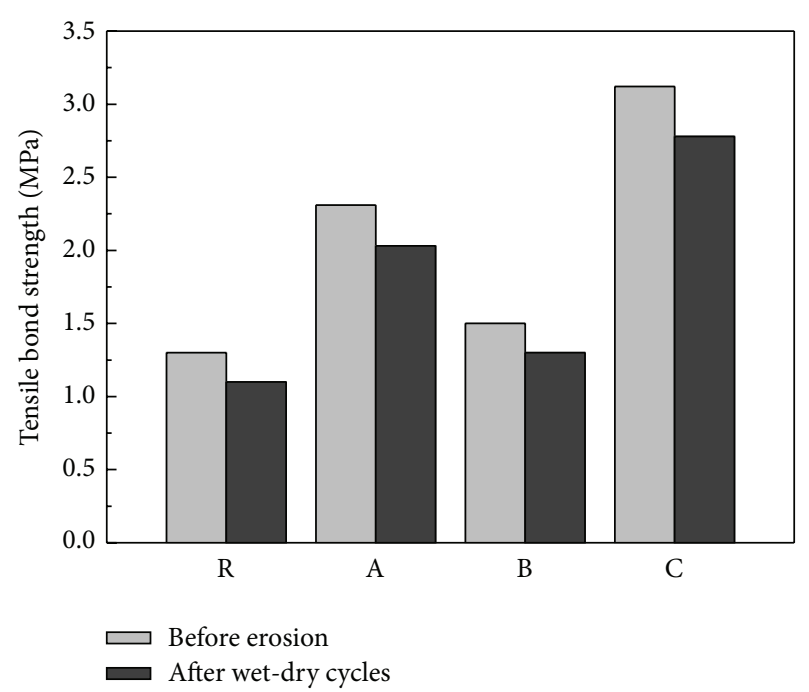

FIGURE 6: Tensile bond strength of repair mortars before and after wet-dry cycles.

of the repair system, whereas the difference in effect among the three kinds of polymers was not significant.

3.1.6. Resistance to Wet-Dry Cycle. Figure 6 illustrates the tensile bond strength of repair mortars before and after wetdry cycles. After wet-dry cycles the tensile bond strengths of all the repair mortars were decreased. The tensile bond strength of ordinary repair mortar was reduced by $25.4 \%$, whereas that of SBR dispersion-, SAE dispersion-, and SAE powder-modified repair mortars was reduced by $13.0 \%$, $21.0 \%$, and $12.8 \%$, respectively. It could be seen that polymers could improve the resistance of the repair system to wet-dry cycles, especially for SBR dispersion and SAE powder.

3.2. Microstructure Observation and Analysis. Above results showed that polymer-modified repair mortars had better bonding property and erosion resistance, but different polymers took effect in different levels. This part would be explained through micromorphology analysis.

3.2.1. Internal Morphology of Repair Mortar. Figure 7 lays out the microstructure of repair mortars observed by SEM. It showed that the ordinary repair mortar had many holes and cracks after being processed by $5 \% \mathrm{HCl}$ solution, while polymer film could be seen clearly in polymer-modified repair mortars. There were four ways of polymer existing in the repair mortars by which the polymer could improve efficiently the properties of the mortar. (1) Polymer formed film in the mortar that could improve the compactness and durability, such as (A1), (B1), and (C1). (2) Polymer film attached on the hydration products and bonded hydration products together that increased the performance of repair mortar, such as (A2). (3) Polymer film attached on the surface of aggregate or bonded to the aggregate and hydration products that increased the strength of repair mortar, such as (A3), (B2). (4) Polymer film formed in the holes or cracks 

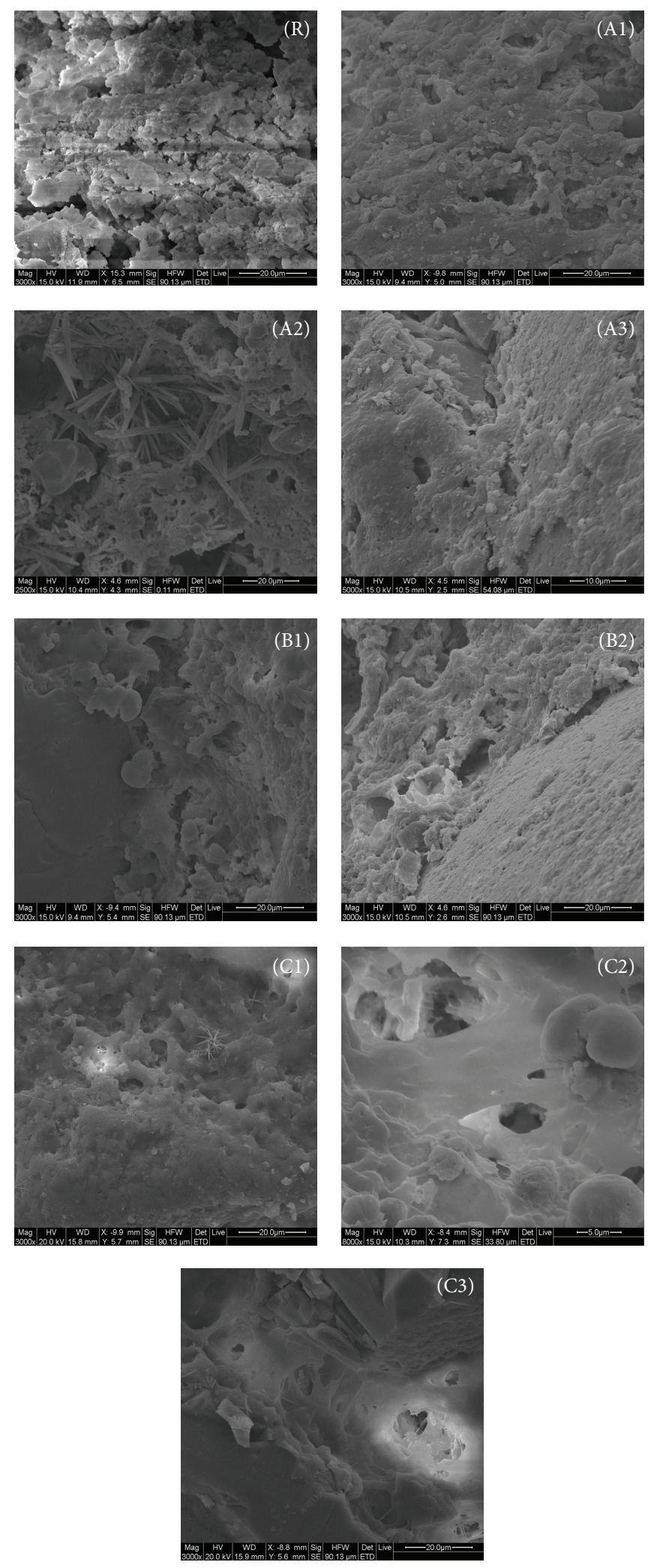

FIGURE 7: Microstructure of repair mortars observed by scanning electron microscope (SEM). (R) ordinary repair mortar; (A1) SBR dispersion formed film in mortar; (A2) SBR film attached on the hydration products; (A3) SBR film attached on the surface of aggregate; (B1) SAE dispersion formed film in mortar; (B2) SAE dispersion film attached on the surface of aggregate; (C1) SAE powder formed film in mortar; (C2) SAE powder film in the hole of mortar; (C3) SAE powder film in the crack of mortar. 

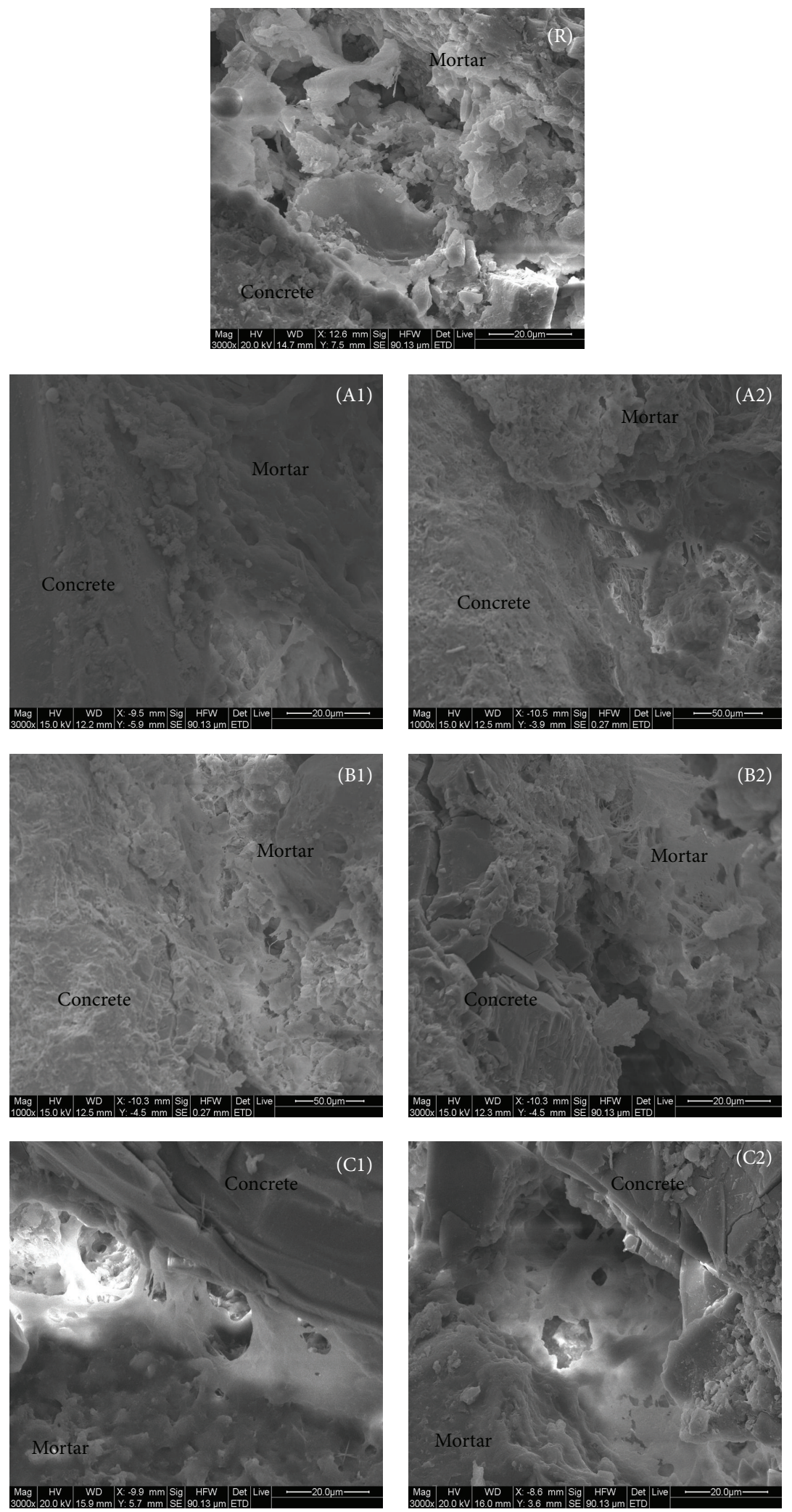

FIGURE 8: Microstructure of interface between repair mortars and old concrete observed by scanning electron microscope (SEM). (R) Interface of ordinary repair mortar and concrete; (A1) SBR formed film at the surface; (A2) SBR formed filament at the interface; (B1) SAE dispersion formed film at the interface; (B2) SAE dispersion formed mesh-like products at the interface; (C1), (C2) SAE powder formed film at the interface. 
of mortar that prevented their further expansion, such as (C2), (C3). The four ways of polymer existing listed above improved the internal structure of repair mortar and thus its performance.

Comparing the internal morphology of three kinds of polymer-modified repair mortars, the polymer film formed from SAE powder looked dense and tough, while the film formed from SAE dispersion looked loose. The film formed from SBR dispersion was in the middle. During SEM observation it was found that the most common way of polymer existing in the repair mortars was like (A1), (B1), and (C1). So this morphology had much more influence on the property of the repair mortar than others. In terms of compactness and completeness, (C1) was the best, (B1) was the worst, and (A1) was in the middle. So it could explain that SAE powdermodified repair mortar had the best bonding property and erosion resistance while the performance of SAE dispersionmodified repair mortar was the worst.

\subsubsection{Morphology of Interface between Repair Mortar and Old} Concrete. Figure 8 lays out the microstructure at interface of repair mortars with old concrete. It showed that there were only some erosive cement hydration products at the interface of ordinary repair mortar with old concrete after being treated by $5 \% \mathrm{HCl}$ solution whereas at the interface of polymer-modified repair mortars not only erosive cement hydration products but also polymer film could be seen clearly. However, the morphologies of the films were different for various polymers. There were three ways of polymer existing at the interface which could improve the bonding property of repair mortar with old concrete. (1) Polymer formed film at the surface and connected the repair mortar and old concrete together, such as (A1), (B1), (C1), and (C2). (2) Polymer formed filament at the interface that connected repair mortar and concrete together, such as (A2). (3) Polymer formed mesh-like products that connected the repair mortar with old concrete, such as (B2). The three ways of polymer existing at the interface enhanced the bonding strength of repair mortar with old concrete and also improved the durability of the repair system.

Comparing the morphology of the three kinds of polymers existing at the interface of repair mortar with old concrete through SEM observation, (A1), (B2), and (C1) were the most common ways of SBR dispersion, SAE dispersion, and SAE powder existence at the interface, respectively, which determined the performance of the repair systems. It was obvious that film formed from SAE powder looked strong, while that formed from SAE dispersion looked loose and that formed from SBR dispersion was in the middle, which gave the explanations that the bonding property and durability of SAE powder-modified repair system were the best.

\section{Conclusions}

Through studying the durability of repair systems of ordinary cement-based repair mortar and three kinds of polymermodified repair mortars with old concrete, the following conclusions were drawn: addition of polymer could increase the tensile bond strength of the repair system and enhance the resistance to erosion by $\mathrm{HCl}$ solution, $\mathrm{H}_{2} \mathrm{SO}_{4}$ solution, saturated $\mathrm{NaOH}$ solution, freeze-thaw cycles, and wet-dry cycles. SAE powder showed the best improvement on the repair system performance among the three polymers; SAE dispersion had the weakest function, while SBR dispersion was in between. Observation on the micromorphology of the repair mortar and the interface of repair mortar with old concrete through SEM gave the reasons. It was found that the polymer film formed from SAE powder was dense and tough; the film formed from SAE dispersion was loose and weak, while the film formed from SBR dispersion was in between, which explained the difference of the tensile bond strength and the durability of the repair systems.

\section{Conflict of Interests}

The authors declare that there is no conflict of interests regarding the publication of this paper.

\section{Acknowledgments}

The authors acknowledge the financial support by the National Natural Science Foundation of China (51202162) and the National Key Project of Scientific and Technical Supporting Programs Funded by Ministry of Science \& Technology of China (2012BAJ20B02).

\section{References}

[1] G. Barluenga and F. Hernández-Olivares, "SBR latex modified mortar rheology and mechanical behaviour," Cement and Concrete Research, vol. 34, no. 3, pp. 527-535, 2004.

[2] M. C. S. Ribeiro, A. J. M. Ferreira, and A. T. Marques, "Effect of natural and artificial weathering on the long-term flexural performance of polymer mortars," Mechanics of Composite Materials, vol. 45, no. 5, pp. 515-526, 2009.

[3] M. H. F. Medeiros, P. Helene, and S. Selmo, "Influence of EVA and acrylate polymers on some mechanical properties of cementitious repair mortars," Construction and Building Materials, vol. 23, no. 7, pp. 2527-2533, 2009.

[4] E. Vincke, E. V. Wanseele, J. Monteny et al., "Influence of polymer addition on biogenic sulfuric acid attack of concrete," International Biodeterioration \& Biodegradation, vol. 49, no. 4, pp. 283-292, 2002.

[5] S. H. Okba, A. S. El-Dieb, and M. M. Reda, "Evaluation of the corrosion resistance of latex modified concrete (LMC)," Cement and Concrete Research, vol. 27, no. 6, pp. 861-868, 1997.

[6] M. Ramli and A. A. Tabassi, "Influences of polymer modification and exposure conditions on chloride permeability of cement mortars and composites," Journal of Materials in Civil Engineering, vol. 24, no. 2, pp. 216-222, 2012.

[7] D. R. Morgan, "Compatibility of concrete repair materials and systems," Construction and Building Materials, vol. 10, no. 1, pp. 57-67, 1996.

[8] J. Bijen and T. Salet, "Adherence of young concrete to old concrete development of tools for engineering," in Proceedings of the 2nd Bolomey Workshop, pp. 1-24, Sion, Switzerland, 1993. 
[9] P. H. Emmons and A. M. Vaysburd, "Factors affecting the durability of concrete repair: the contractor's viewpoint," Construction and Building Materials, vol. 8, no. 1, pp. 5-16, 1994.

[10] R. A. Bass, R. L. Carrasquillo, and J. O. Jirsa, "Shear transfer across new and existing concrete interfaces," ACI Structural Journal, vol. 86, no. 4, pp. 383-393, 1989.

[11] G. J. Xiong, J. W. Liu, G. Y. Li, and H. Xie, "A way for improving interfacial transition zone between concrete substrate and repair materials," Cement and Concrete Research, vol. 32, no. 12, pp. 1877-1881, 2002. 

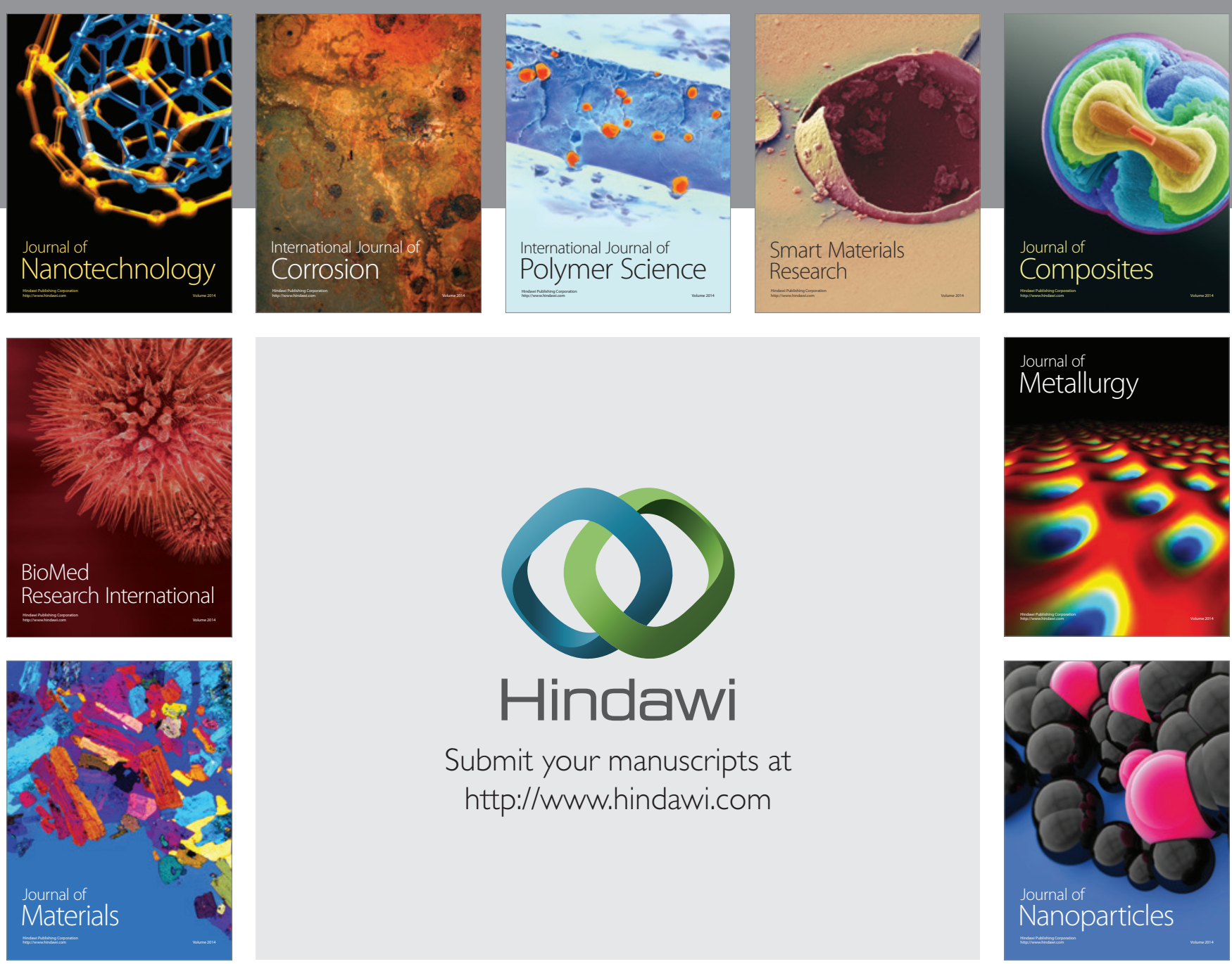

Submit your manuscripts at http://www.hindawi.com
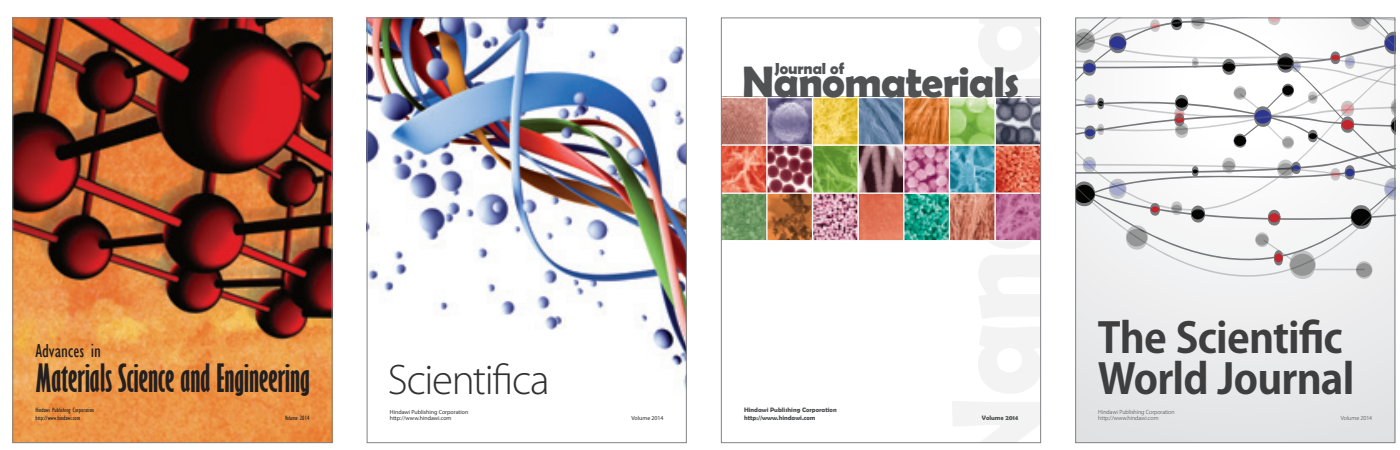

\section{The Scientific World Journal}
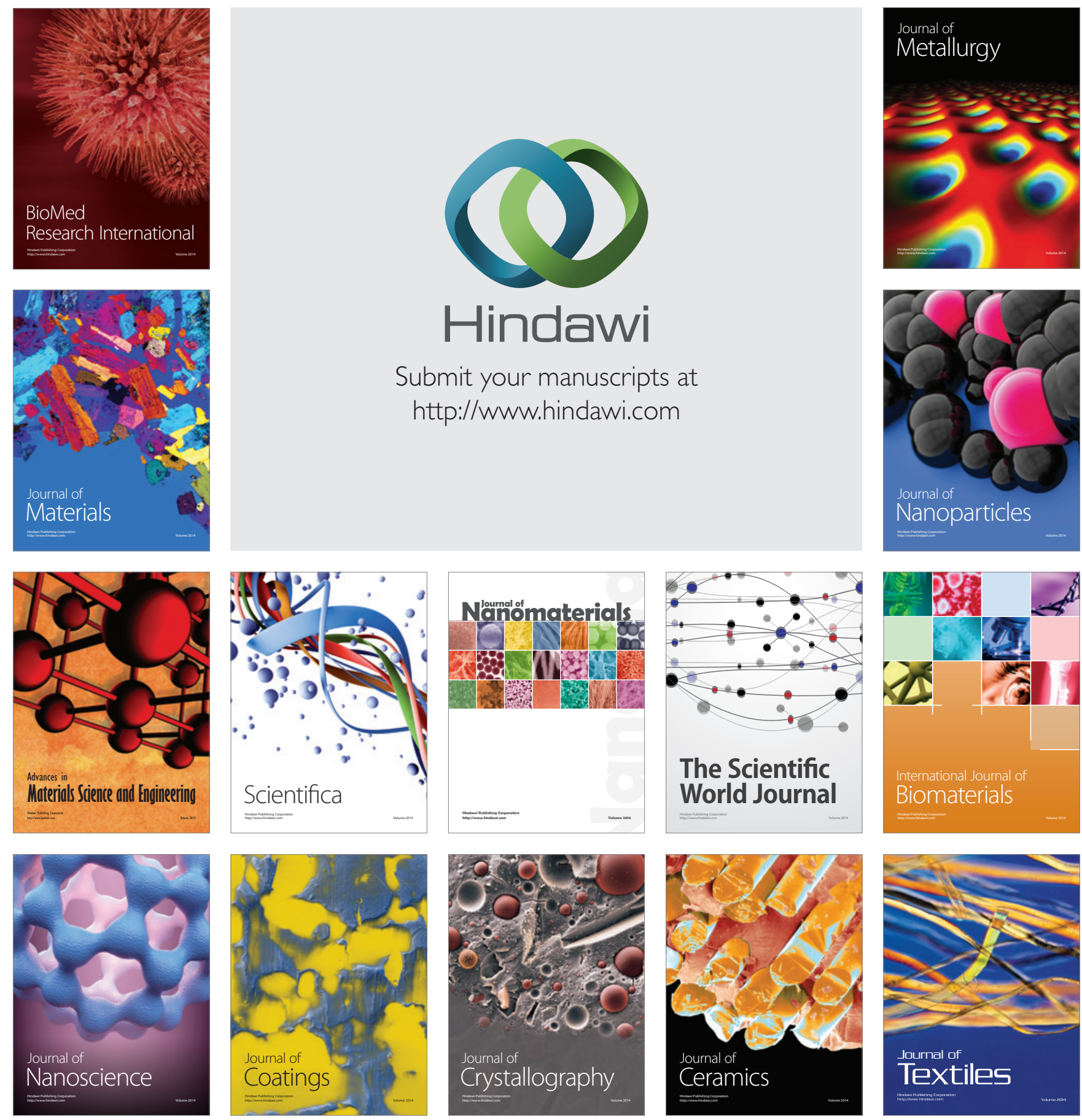